\title{
Truth in Sport
}

\author{
Tomasz Michaluk
}

\author{
AWF Wrocław, Poland
}

ABSTRACT

The classical definition of truth, as the correspondence of something we can call facts and our image of them, applies to discussing those sports where a result is established by simple and unequivocal evaluation, based on sensory perceptions. In the most popular athletic contests, we do not perceive who wins, but we know the result of a measurement, which is later interpreted as the victory or taking a further place. The reading of a measuring device only represents the result, which does not mean that it really is the result. We do not know the real result; by reading the digits on the screen, we already read a sign. Subsequently, it can be interpreted as the sign of victory. We assume that by improving our measuring methods we approach the true representation of the results. It would be, however, naive, to claim that this process will lead to the measurement ceasing to represent and starting to be the represented object, unmediated through any signs. Therefore, apart from the classical conception of truth, we can define truth in sport semiotically as representation, and subsequently interpretation, of a sporting event, performed by the referees and spectators. In this definition truth is sanctioned by the referee's decision, not necessarily based on facts.

Some professional sports can be compared to science. A scientific experiment must observe strictly defined conditions and take into account factors valid for its course and results. The conditions of a "sporting experiment" are strictly defined and their correctness is guarded by men and machines. In science, the discovery of a falsehood disqualifies a given "scientific event"; in sport a mistake or breaking the rules can become a controversial decision or a refereeing mistake, and usually are not changed or reviewed, turning into the "truth of sport".

KEYWORDS semiotic, semiotics of sport, philosophy of sport

\section{Background (Introduction)}

The differences between the results of the best competitors in sports like running and swimming are perceivable only due to the progress in strictly scientific measurement techniques. Throughout decades, the records are beaten by mere centimetres and hundredths of a second. People engage in sports but the human senses cannot decide who has won and consequently a competitor ceases to stand out as the winner. The triumph and the outburst of joy is preceded by hesitation before the machine shows the verdict. Technology suggests what the referees will accept as truth and who will carry off the prize, and subsequently the spectator-interpreters sanction the victory, making it meaningful and spreading the news about it. A sporting event is significant as a cultural fact and gains 
importance only due to the process of former or subsequent interpretation. ${ }^{1}$

Sporting competitions are held according to strictly defined and unequivocal rules, which cannot be modified during the course of a given sporting event. Taking the matter from the formal point of view, if a game does not follow regulations accepted by organisations and associations recognised in the sporting world, it does not fulfil the criteria of a given sport and is not "professional", i.e. the results are not considered credible or true ${ }^{2}$. Each potential departure from the metrically defined conditions of an agon implies disqualification of the results. If the differences between the results of the best competitors can be measured only in hundredths of a second or in millimetres, a measurement error on a similar scale may determine a new world record. These are the conditions defining professional sport and distinguishing it from, for instance, recreation or physical education as a school subject. People who play volleyball, hockey or football recreationally do not need to worry about the number of players, the exact height of the net, the size of the pitch or the lack of a referee or an observer from an association connected with a given sport, where they should belong by definition ${ }^{3}$.

Professional sport can be compared to science. A scientific experiment must abide by strictly defined conditions and take into account factors which are assumed to be important for its course and result. It is equally important that an experiment should be repeatedable, in possibly the same conditions, independently of a place and an experimenter. The conditions of a "sporting experiment", which is a sporting competition ${ }^{4}$, are strictly defined and their regularity is guarded by people and machines alike. In a sporting event the only variable should be the result achieved by a to some extent standardised sportsperson in strictly defined conditions. The state of a competitor's organism is monitored by scientific tests to detect any chemical substances boosting its efficiency. Other limitations resulting from the regulations governing a given sport may concern age, weight, sex, etc.

Therefore, although professionalism in sport is usually recognised teleologically, as a situation in which playing a sport constitutes the source of income for a competitor, from the formal point of view professional sport fulfils conditions similar to those ruling scientific experiments. It is probably those two criteria - teleological and formal - that appear together and define a sport as a profession. It is possible for an amateur to make financial gain by, for example, winning the Wroclaw Marathon ${ }^{5}$, which basically meets the above mentioned criteria for professionalism. A further specification therefore becomes necessary: for a professional sportsperson, taking part in payable competitions is cyclical and unlimited by where and when the competitions are held. This condition excludes amateur participants, who occasionally take part, when a contest is organised close to their home. A professional sportsperson undertakes the effort of participating in a contest after having calculated potential costs against potential gains in terms of both finances and ranking. Consequently, an amateur may win the Wroclaw Marathon and earn money from it, while a professional sportsperson can take a

\footnotetext{
${ }^{1}$ An Olympic gold medal can be won with a result weaker than those achieved by competitors during less important competitions. What really matters, though, is being an Olympic gold medallist, not achieving a better result a day before the Games.

${ }^{2}$ If the men's 100 is actually held over a distance of 99.90 metres and this distance is the basis for time measurement, it is not true that a competitor achieved the measured time after running the distance of 100 metres.

${ }^{3}$ For example, the Polish Football Association defines directly who is considered by them to be a football player: "a football player - a competitor playing football, registered by the PFA or by a Voievodeship Football Association". And concerning the rules: "Football is played according to the rules of the game, which can be issued and changed only by the International Football Association Board (IFAB)". http://www.pzpn.pl/statut_pzpn.php [13.10.2008].

${ }^{4} \mathrm{~A}$ sporting event is constituted mainly by: competitors, referees, and spectator-interpreters.

${ }^{5}$ In the $26^{\text {th }}$ Wrocław Marathon, held on 14 September 2008, the basic prize for first place was 11,000 PLN (about $\$ 5,000)$.
} 
lower place and suffer loss, which is a professional risk. Formally speaking, according to the regulations, it bears no practical meaning what the intentions behind the competitors' participation in a sporting event are.

Is there any relation between the empirical standards accepted in given times in the course of scientific research and the conditions with which a professional sporting event must comply? Yes, because technology based on scientific theories plays an increasing role in deciding what truth in sport is, transferring assumptions and criteria of correctness of the methods in use into the sphere of sport, together with falsificationism (falsifiability), which in sport could be expressed thus: "An established result of a sporting event stems from the adopted methods of evaluation and measurement, whose theoretical background will undergo changes and which will become falsified by future scientific discoveries that will establish newer methods of research and measurement, generating results closer to the truth". If, from the formal point of view, professional sport meets criteria similar to those applied in scientific research, it becomes valid to consider to what extent the question of truth is a significant issue to be researched by the philosophy of sport.

\section{Material and Methods}

\section{Truth in sport - the epistemological-ontical view}

To what extent does truth determine the essence of a sporting event? Can the classical truefalse dualism be applied in the evaluation of the course and result of sporting events? To what extent is the aim of a sporting event the representation of truth?

Sporting events are mediated through signs, which always have empirical facts as their basis; facts such as readings of electronic devices, direct observations, impressions of the contest held, etc. One of the goals of the representation of the real world through the sign relation is true representation. The reading of a clock is therefore the sign of the time, in which a sportsperson has completed a distance, and joining those two elements in a relation is a process of interpretation, of constituting sign-interpretants by interpreters. The assumption that all cognition is mediated through signs forms the basis of C.S. Peirce's semiotics, which I adopt as a methodological basis for my research into the phenomenon of sport ${ }^{6}$. A sign is a triadic relation, joining a sign and its object through the third counterpart of the sign relation, i.e. an interpretant, which is also a sign and can constitute an element of other triadic sign relations. Therefore there exists a continuity of sign processes (synechism), which develop through subsequent representations and interpretations.

The longest jump or distance covered by a javelin or shot-put throw, or the fastest time for completing a given distance in running or swimming, seem to be unambiguously ascertainable thanks to modern technology. However there are cases in the modern history of the Olympic Games in which controversial decisions were taken in situations that were clear from the perspective of modern technology and standards. During the Olympic Games in Rome in 1960 in the men's 100m freestyle, an electronical measuring system was used in addition to visual observation. Its readings showed that in the final race the fastest time belonged to an American, Lance Larson (55.10 seconds) and not to the official winner, the Australian John Devitt (55.16s). In those times referees based their decisions mainly on visual observations, even without the use of video replays. These visual observations were the basis for pronouncing Devitt the winner, although even here the referees were not unanimous. Time measurements were taken manually and there were three independent measurements for each

\footnotetext{
${ }^{6}$ The outline of the semiotic method based on C.S. Peirce's semiotics has been defined by me in: Michaluk, T. (2007) Selected Aspects of The Semiotics of a Sporting Event. In Physical Culture and Sport. Studies and Research, 1 Volume (XLV), Warszawa: AWF.
} 
lane and contester. For Devitt they were identical, 55.2 seconds each time, whereas for Larson they varied: 55.0, 55.1 and 55.1. Although the fact that Larson's time was faster was shown by both visual observations and automatic (additional) measurement, the referees pronounced Devitt the winner, thereby depriving Larson of an Olympic gold medal. The main referee, Hans Runströmer from Germany (BRD) decided to add (sic!) one tenth of a second to the American's result to sanction his decision. Because of this official records show that the results of Devitt (in first place) and Larson (in second) are the same, i.e. 55.2 seconds. The statement "John Devitt won the men 100 freestyle final during the Olympic Games in Rome" does not tally with the actual state of things at the time, which can easily be proved, for example by the use of video recordings. The case can be analysed using the traditional correspondential definition of truth; the referee Runströmer's decision undoubtedly sanctioned untruth. Consequently, due to the progress in scientifically based technology, the method of visual observation has been falsified by the method of automatic measurement.

In a part of competitions the victory is determined by a relatively simple measurement of a single act (the above mentioned time, distance, distance from the bull's eye, etc.), provided that the competitor has performed the act according to regulations and for example has not overstepped the line, which would result in the disqualification of a given attempt. In such cases any mistake on the part of a referee, aided by electronics, seems to be contemporarily excluded, and, more importantly, indisputably unacceptable for the participants of a sporting event, especially spectators, who due to technology also have the full picture of the situation. It is highly improbable that a situation like that from 1960 in Rome, i.e. the undermining of the automatic measurement by an arbitrary human decision, could take place in the $21^{\text {st }}$ century. Electronics has become a referee and its verdicts are not questioned. People with their perceptive abilities must believe in the credibility of electronical measurements, because they themselves are not able to discern any differences during the course of a sporting event. For a part of sports, from the epistemological point of view, the question "Who is the winner?" is unanswerable on the basis of sensory perception. In reality we do not know who wins, we just know what the electronic devices say. What remains is a question of an ethical nature: is this a desirable situation in sport?

There are sports where a human referee still competes successfully with electronical devices. In team games, where the victory is determined by scoring a maximum number of points, i.e. goals or accurate shots, in a given time, the decision on whether the point has been scored according to the rules of the game depends on the experience and abilities of a referee or umpire. Mistakes in refereeing a match can lead to scoring a point or even stopping the game in a decisive moment, which can result in an undeserved victory. Is a referee universally censured and the result cancelled in the case of an obvious refereeing mistake? Not at all, even though the final result is based on wrong decisions which are not adequate to the situations in the course of the play, and even though the result does not stem from facts and in the classical definition of truth does not represent reality. Examples of referees' mistakes are easiest to find in team games, which can result from the number of players, the size of the pitch and the dynamics of the game. In football, bigger or smaller mistakes in refereeing occur practically in every match, regardless of their importance. Therefore, if a single mistake were disqualifying for the whole game, probably a huge part of the results would have to be wiped from the records. I want to make it clear that the situation where a referee does not notice an incident for reasons independent of him, like having his back turned to the players when one of them pushes or trips up another. A mistake is, for instance, awarding a penalty for reasons which did not take place; for example, a football referee thinks (has the impression) that he noticed a player in the penalty area deliberately touching a ball with his hand, which in fact did not take place as can be proved using photos, video records, close-ups and replays. Therefore, on the basis of a wrong judgement, which can be simplified to "A player touched the ball with his hand in the penalty area", a referee undertakes 
actions which can considerably influence the final result. Undoubtedly, human perceptive abilities are limited and the judgement based on sensory perceptions, as a source of truth, is highly fallible. The limits of tolerance seem to be the case of the famous footballer Diego Maradona. In a quarter final match during the 1986 World Cup he directed the ball into the goal with his hand, feigning to head it. The referee allowed the goal, Argentina won the match, and subsequently the World Cup too. A mistake or a deception?

While discussing football, it is worth observing that some doubts, in the context of truth understood as simple concordance with facts, can be raised concerning the timing of matches, as the true time of the game is usually different from that shown by the clocks. The duration of a match according to regulations is 90 minutes $(2 \times 45)$. Usually a few minutes are added to each half. It is the referee's decision, based on breaks in the course of the game, resulting, for example, from the necessity to provide medical help to one of the players. The first half, from the beginning to the final whistle, may last, for instance, 48 minutes. Yet after the break the time is counted from the $46^{\text {th }}$ minute; the time added to the first half is omitted. Let's assume that a goal is scored in the second half, 10 minutes from its start. Is it scored in the $55^{\text {th }}$ minute or $58^{\text {th }}$, if the referee added 3 minutes to the first half? Stating that the goal was scored in the $55^{\text {th }}$ minute is undoubtedly a false judgement.

There exist sports, where a part of the evaluation of a sportsperson is made up of factors that cannot be unequivocally, numerically classified. Decisions of a number of equal referees vary and therefore an average is taken. The differences do not stem from better or worse perception of truth, because there is no one truth, ascertainable by objective measurement techniques. Even though individual technical or formal elements can be evaluated in a binary way: well/badly, or correctly/incorrectly executed (a jump, a figure, etc.), the artistic quality, style and precision are not binary and probably to an indefinite degree dependent on extra rational factors influencing the evaluators. Such a factor can be for example the place where a contest is held. In what way is it true that one competitor presented better artistic quality? In sports which allow such evaluative criteria, the classical concept of truth loses meaning for the sake of the evaluation of the situation dependent on the axiology of the people who take decisions.

The truth of sport is not necessarily founded in facts and for a part of sports not even on observational statements. The issue of truth in sport can be defined on at least two complementary levels. On the first one we observe the "classical" finding of "facts" with the help of methods applicable due to the technology accepted as credible in given times. In this respect the progress in nearing the truth is correlated with the progress in science and liable to falsification in the same way as scientific methods. The result provided by electronic devices only represents the time for completing the distance, the length or height of a jump, etc. Representing in this case does not mean being. The real time of the run is in no way given to us directly, so by reading off digits from the clock we read what is already a sign. In a further process this sign can be interpreted as the sign of victory. We assume that improvements of the measuring techniques bring us nearer to the true representation of the factors significant for a sportsperson's evaluation. It would be naive, though, to assume that this process will ever cause the reading of an electronical device to cease to represent and start to be the represented object, unmediated through any signs.

When the signs binding a competitor to a result have already been constituted, the further step is the interpretation of these signs through the signs of victory, loss, the place taken, etc. The case of Devitt and Larson, unfortunately in a pathological way, is a good example of this process. Establishing the material truth, that is constituting an index binding Larson to the time he achieved, did not cause Larson to be pronounced the winner. It was only the process of interpretation, influenced by factors unconnected with sport, that led to signs, and which bound Devitt to victory. Devitt was crowned the 
winner thanks to the signs that connected victory with his person, and this connection was illegitimately made by the main referee of the contest.

\section{Truth in sport - the normative view}

Is truth the dominant value represented by sport? The classical definition of truth, as the correspondence of something we can call facts and our image of them, can find only limited application in discussing only those sports where a result is established by simple and unequivocal evaluation, based on visual or other sensory perceptions. In the most popular athletic contests, especially those held in Olympic Games like 100 metre running or swimming, we do not perceive who wins, but we do know the result of a measurement, which is later interpreted as a victory or taking a further place.

However, if we assume that truth is one of the dominant values in sport, as is decisive in achieving the sense of a game, i.e. finding the winner, a great inventiveness is necessary to justify the conservative stance of a part of the sporting milieu, closing themselves to all technical improvements in refereeing. Naturally this inflexible stance can be explained by the fact that new solutions are not sufficiently tested. This is, however, a dubious argument, as no technology can possibly rival the number of errors committed by human referees. Technology should aid and not replace people. De facto, it already aids them, which can be proved, for instance, by the ear-pieces worn by football referees. However, no formalised improvement in the quality of refereeing follows. Resistance shown in some sports against the opportunities created by modern science can be the result of the adopted axiological system, in which progress is thought to signify and imply undesirable domination of technology over man.

We experience in sport a surprising disparity between the evaluation of the work of competitors and referees. On the one hand, we witness numerous disqualifications of competitors on the basis of circumstances and facts discovered even relatively late in the day, and consequently the competitors being stripped of titles and medals even after the contest is finished. On the other hand, we see situations where no sporting authorities present react even when mistakes in refereeing are immediately apparent. Is the basis of this state of affairs a general conviction that a competitor is always inclined to purposeful deceit, whereas a referee remains honest even when taking controversial decisions?

The quick spreading of doping and ways of discovering doping in the $20^{\text {th }}$ century has caused a wave of scandals following the discovery of illegal attempts by many sports stars to boost their organisms' efficiency. A remarkable case is that of the Canadian runner Ben Johnson, who was disqualified and stripped of the gold medal he won during the men's $100 \mathrm{~m}$ in the Olympic Games in Seoul in 1988. In 1991 Johnson was allowed to take part in competitions again, and in 1993 he was banned for life, as during the athletic contest in Montreal illegal chemical substances were again discovered in his organism. After this scandalous affair all the records achieved by the Canadian sprinter were cancelled. This scandal reverberated in other spheres of culture and drew the attention of the whole world to the pathologies of professional sport, where achieving a record pushes the abilities of the human organism to the very limits. Johnson's cancelled record, achieved on doping in the men's $100 \mathrm{~m}$ in Seoul, is 9.79. After Johnson's disqualification the gold medal went to Carl Lewis, who ran the second-fastest time -9.92 seconds, being at the same time a new Olympic record.

In 2008 in Beijing the Jamaican sprinter Usain Bolt beat the world record on the same distance with the result 9.69. In 1988 Johnson on doping was worse by 10 hundredths of a second and Lewis, without doping, by 23 hundredths, than Bolt in 2008. Taking into account the twenty years that passed 
from Seoul to Beijing and the difference in results, we can claim that on average the result in the men's $100 \mathrm{~m}$ improves by a little more than $1 / 100$ of a second per year, or that each year in the same time a competitor runs a distance longer by about 1 centimetre. What is the mechanics of fame achieved by beating this particular record? Although it is sometimes possible to discern the differences in arriving at the finish among the competitors in the same race, is it at all possible to compare different contests and point to which competitor achieved the best time? Is it intriguing to what extent the above mentioned results, varying in a way imperceptible to the human eye, are true in the sense of being in concordance with the facts? From the point of view of the semiotics of sport, the truth has been finally sanctioned by the decision of the referees as the privileged interpreters; the truth as the concordance of the results with the reality is of secondary importance, as it is not possible to repeat the contests, which were singular acts. This is the difference between a sporting event and a scientific experiment, which can be repeated any number of times. In this context each sporting event is unique, from which stems the great importance of the conditions under which it is held.

Johnson's case is unequivocal, because in common opinion doping rejects the idea of fair play in sport. The native American Jim Thorpe (Wa-Tho-Huk) in 1913 was deprived of his medals and his records from the Olympic Games in Stockholm in 1912 were cancelled, following the discovery that a few years earlier (1909-1910) he played professionally for two seasons in the second baseball league. Jim Thorpe died in poverty in 1953. It was only in 1983 that this outstanding sportsman was rehabilitated and his family regained the medals he honestly won.

In the axiological context even more puzzling is the situation during the Olympic Games in London in 1908, when the marathon course was lengthened by moving the start and the finish to positions more convenient for the observation by the English court. The Italian runner Dorado Pietri would have been the winner, if the marathon had been of the distance assumed before the beginning of the Olympic Games, but he was disqualified for leaning against spectators on the metres that had been added.

In the above described cases of B. Johnson and J. Thorpe, the competitors were handed the biggest punishment possible in professional sport, a lifetime disqualification, but for totally different reasons. In the case of the Canadian sprinter science with its research methods was a decisive factor. In the times when Thorpe was punished, sporting authorities adhered rigorously to the rule that only amateurs who do not earn even the smallest financial profits from sport can take part in the Olympic Games. This rule has evolved during the $20^{\text {th }}$ century to the point where the professionalism of sportsmen, especially the Olympic players, has been accepted, because no efficient method was found to check whether a given contester really does engage in amateur sport without the financial support of any organisations, governments, companies, etc. Thorpe did not break the rules directly in the course of a sporting event. His disqualification resulted from the axiological stance, from which a conviction stemmed that modern Olympic Games should be unquestionably for amateurs. In the first decades of the $20^{\text {th }}$ century losing the status of an amateur by a sportsperson was like a woman losing her virginity. A competitor lost it once in his lifetime when he took money for participating in a sporting event for the first time and could never regain it. It is surprising that Thorpe was disqualified for the Olympic Games in 1912, and Pietri for the marathon, lengthened to satisfy the wishes of the court, in the Games in 1908. Apparently the organisers of the Games did not adhere very strictly to the rules, manipulating the formal conditions freely, and at the same time disqualifying the competitors for "offences" resulting from a quasi-necessary interpretation of the idea of modern Olympic Games. I must remind readers here that Pietri ran on his own the distance planned as the marathon before the Olympic Games, leaning on the spectators only on the added "royal metres". 


\section{Conclusions}

Truth in sport, true result and the ranking based on it, is not a goal of sport in the traditional Aristotelian correspondentional view, because it is not its dominant value, although it is a necessary factor in deciding who the winner is. The reality of sport is built on the real world and mediated through referees and the organisers of contests, who decide about the course of a competition and rank contesters according to the results they themselves have accepted. Technology can support referees, but they are not absolutely obliged to accept its verdicts.

There exist different degrees of sensitivity to truth in sport. If, with the help of modern measuring techniques, it is established that during the competition a contester's organism differs from accepted chemical and biological norms, the consequence is disqualification, together with cancelling all the results and taking back all the titles and medals. Even a suspicion of doping can have very unpleasant consequences, casting a shadow on a competitor's good name. However, if a referee's mistake makes one contestant or a team a winner in an "all or nothing" competition, this wrong decision is not changed. The argumentation that allows the toleration of a referee's mistakes is axiological or semiotic in nature.

The truth of sport usually represents facts, but this is not a conditio sine qua non of the meaningfulness of a sporting event. Although the evaluation of a player's performance meets the criteria of modern scientific methodology, including falsificationism, referees' work is based on a method, which could be described as "absolutistic". If a referee (belonging to an official association) accepts something as true, the decision he has taken can correspond to the actual situation as well as imitate truth, preserve falsehood, create an illusion of sport in the very eyes of the participants of the sporting event. A referee in sport is assured of his infallibility and endowed with greater power than Cartesian ratio in science, because he has the power of creation, which sometimes turns him into the Malicious Demon. Although Descartes' method did not bring the expected results in science, in sport absolutism defends itself with the help of the axiomatic system. A referee is transcendent to the values which under his eye must rule the behaviour of competitors. He evaluates the course of competition and creates "sporting facts", himself not being subject to such rigorous evaluation.

In science the discovery of a falsehood disqualifies a "scientific" event; in sport it can be a controversial decision, which does not yield to change or repetition and evolves into the "truth of sport". It is axiology that is responsible for this state of affairs, as in such a valid question as refereeing it only to a limited degree allows the use of modern methodology based on scientific standards, which has been successfully used for years in relation to sportsmen. 